\title{
Morphogenesis of Mandibular Dental Arch Shape in Human Embryos
}

\author{
ALPHONSE R. BURDI \\ Department of Anatomy, The University of Michigan, Ann Arbor, Michigan
}

Changes in shape of the mandibular dental arch were demonstrated in a developmentally representative sample of human embryos. Each reconstructed arch was described in terms of a conformance to a reference geometric curve; ie, catenary. Cross-sectional sample trends showed that the initial dental lamina is anteroposteriorly flattened during the sixth week and begins a progressive elongation and conformance to the catenary curve in 81/2-week embryos.

There is no one reference standard that describes the early prenatal development and subsequent changes in the shape of the postnatal human dental arch. Arch shape has been described qualitatively by using such geometric terms as semiellipsoid, paraboloid, U-shaped, rotund, and horseshoe-shaped. In a quantitative study, MacConaill and Scher ${ }^{1}$ have suggested that the postnatal form of the dental arcade can be described by a catenary curve. Scott ${ }^{2}$ concurs, and has stated that the arrangement of embryonic tooth germs and their parent dental lamina also conform to a catenary curve as they differentiate. In a refinement of Scott's observations, Burdi and Lillie ${ }^{3}$ have supported this observation of prenatal catenary dental arch shape. They have reported that the maxillary dental lamina first appears late in the sixth week in utero as an anteroposteriorly flattened arch, and that it does not conform to a catenary curve until approximately $91 / 2$ weeks in utero.

Those who have used the catenary curve for descriptive purposes recognize that its choice as a reference standard is arbitrary. This curve is simply defined as a geometric curve simulated by a chain of many links

This investigation was supported in part by USPHS Grant HD-00178 from the National Institute of Child Health and Human Development, National Institutes of Health, Bethesda, Md.

Received for publication May 22, 1967. that hangs freely from the supported ends. It serves as a convenient quantitative expression of dental arch shape. Other geometric curves might have been used.

The primary question of this study is whether the shape of the human mandibular dental arch can be described by a catenary curve during embryogenesis. If so, there may be discernible time-linked and directional growth trends that could be correlated with the dynamics of growth in contiguous facial regions. Such a study would complement the few existing quantitative reports that emphasize the biological continuum of dental arch development and would perhaps provide some basis for understanding the ontogeny of clinically aberrant dental arch shapes.

\section{Materials and Methods}

Fifteen human embryos were studied. They were free of gross cephalic defects and $6 \frac{1}{2}$ through 12 weeks of age in utero (20 through $75 \mathrm{~mm}$, crown-rump length). This cross-sectional sample represented stages in tooth development from the appearance of an uninterrupted dental lamina to the progressive appearance and cytologic maturation of the ten mandibular deciduous dental enamel organs (Table 1 ).

Each embryo was first studied by light microscopy to evaluate developmental stages of mesodermal and ectodermal components of each tooth germ. For this purpose, embryos were fixed in $10 \%$ neutral buffered formalin, frontally sectioned at $10 \mu$, serially mounted and stained with either a Masson trichrome stain for connective tissue or with hematoxylin and eosin. Changes in dental arch shape and size were measured by using graphic reconstructions ${ }^{3}$ of the circumoral complex of each specimen.

Photographs of each graphic reconstruction were used to indirectly measure changes in size, proportion, and geometric arch form: 
ie, shape. The quantitative comparisons of dental arch shape with the catenary curve required the design and use of a catenometer, which consisted of a $200-\mathrm{mm}$ fine-linked chain suspended at each end from a rigidly mounted vernier caliper (Fig 1). The chain was soldered to the end points of the caliper. The apical loop of the freely hanging chain defined the catenary reference of the study. Each photograph was then aligned in a grid coordinate system behind the hanging chain to reduce any parallax. The chain was next

TABLE 1

Chronologic and Developmental. Tooth Stages of Embryos Used in This Study*

\begin{tabular}{|c|c|c|c|c|}
\hline No. & $\begin{array}{l}\text { Embryo } \\
\text { No. }\end{array}$ & $\begin{array}{l}\text { Crown-Rump } \\
\text { Length }(\mathrm{mm})\end{array}$ & $\begin{array}{l}\text { Fst. Age } \\
\text { (Weeks) }\end{array}$ & Characteristic Features of Tooth Development \\
\hline 1 & EH 600 & 20 & 6.5 & $\begin{array}{l}\text { Budding proliferation of dental lamina at } 4 \text { sites } \\
\text { showing flattened surface cells and a basal layer } \\
\text { of low columnar cells continuous with basal } \\
\text { layer of oral epithelium and a more central mass } \\
\text { of large polyhedral cells. Sites correspond to } \\
\text { central incisors (2), lateral incisors (2). Lamina } \\
\text { of distal arch present with a slight indication of } \\
\text { budding in molar region. }\end{array}$ \\
\hline 2 & EH 880 & 24 & 7.5 & $\begin{array}{l}\text { Similar to general stages of development of } \\
\text { EH } 600 \text {; dental organs are in the bud stage and } \\
\text { appear fused. }\end{array}$ \\
\hline 3 & EH 231 & 21 & 7.0 & $\begin{array}{l}\text { Budding proliferation clearly at } 6 \text { sites: central } \\
\text { (2) and lateral (2) incisors and canine }(2) \text { dental } \\
\text { organs. Region of distal dental lamina in molar } \\
\text { region shows some differentiation. }\end{array}$ \\
\hline 4 & EH 739 & 22 & 7.0 & $\begin{array}{l}\text { Similar to general stages of development of } \\
\mathrm{EH} 231 \text {. }\end{array}$ \\
\hline 5 & EH 892 & 27 & 8.0 & $\begin{array}{l}\text { Similar to general stages of development of } \\
\text { EH } 231 \text {. }\end{array}$ \\
\hline 6 & $\mathrm{EH} 785$ & 35 & 8.5 & $\begin{array}{l}\text { Ten dental organs present: central and lateral } \\
\text { incisors present in their early cap stages; canine } \\
\text { and first molar organs are in a characteristic } \\
\text { midcap stage and second molar is present in } \\
\text { bud stage. }\end{array}$ \\
\hline 7 & EH 946 & 34 & 8.5 & $\begin{array}{l}\text { Similar to general stages of development of } \\
\text { EH } 785 \text { except second molars (2) present in } \\
\text { early cap stage. }\end{array}$ \\
\hline 8 & EH 523 & 36 & 8.5 & $\begin{array}{l}\text { Similar to general stages of development of } \\
\text { EH } 946 \text {. }\end{array}$ \\
\hline 9 & EH 479 & 36 & 8.5 & $\begin{array}{l}\text { Ten dental organs present: central incisors (2) } \\
\text { and first molars (2) present in early cap stage; } \\
\text { lateral incisors (2) and canine dental organs (2) } \\
\text { present in midcap stage; second molar organs } \\
\text { (2) in late bud stage. }\end{array}$ \\
\hline 10 & EH 678 & 30 & 8.0 & $\begin{array}{l}\text { Ten dental organs present: central incisors (2) } \\
\text { in early cap stage; second molars }(2) \text { in late bud } \\
\text { stage; remaining } 6 \text { organs present in midcap } \\
\text { stage. }\end{array}$ \\
\hline 11 & EH 15A & 30 & 8.0 & $\begin{array}{l}\text { Central incisors (2) and second molars (2) } \\
\text { present in early cap stage; remaining } 6 \text { organs } \\
\text { present in midcap stage. }\end{array}$ \\
\hline 12 & EH 882 & 29 & 8.0 & $\begin{array}{l}\text { Ten dental organs present in their midcap stage } \\
\text { of development with the exception of both } \\
\text { second molar organs which are in early cap } \\
\text { stage. }\end{array}$ \\
\hline 13 & $\mathrm{EH} 356$ & 45 & 9.0 & $\begin{array}{l}\text { Similar to general stages of development of } \\
\text { EH } 882 \text {. }\end{array}$ \\
\hline 14 & EH 784 & 55 & 10.0 & $\begin{array}{l}\text { Ten dental organs present: central incisors (2) } \\
\text { present in late cap stage; second molars (2) in } \\
\text { early cap stage; remaining organs present in } \\
\text { midcap stage. }\end{array}$ \\
\hline 15 & EH 628 & 75 & 12.0 & $\begin{array}{l}\text { Full complement }(10) \text { of mandibular deciduous } \\
\text { dental organs present in late cap stage except } \\
\text { for lateral incisors which appear to be in their } \\
\text { early bell stage. }\end{array}$ \\
\hline
\end{tabular}

* From the Embryological Research Collection, Department of Anatomy, The University of Michigan. 


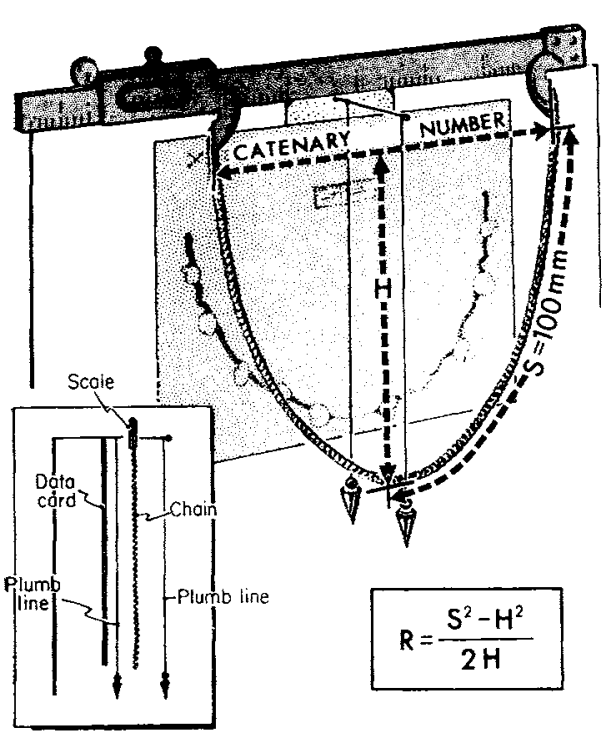

FIG 1.-Catenometer built on vernier caliper shows the best alignment of the catenary chain on mandibular dental arch. Dimensions used in the catenary analyses are also shown. Left inset is a side view of the catenometer. The simplified catenary formula for determining apical arch curvature $(R)$ is shown, right.

registered, by inspection, on each reconstruction either (1) to cover the lateral and posterior-most portions of the dental lamina whenever it was the predominant structure, as in younger embryos, or (2) to pass through the greatest number of dental organs, as in older specimens. Finally, the character of alignment of the arch, chain, and coordinate system was recorded photographically.

Arch shape was quantitatively described by using a formula simplified by MacConaill and $\mathrm{Scher}^{1}$ in their analysis of adult dental arches. The radius of curvature $(R)$ of the catenary at its apex was determined by the formula $R=\frac{S^{z}-H^{2}}{2 H}$. The value $R$ is a quantity that defines any catenary curve uniquely, just as the radius of a circle defines that circle uniquely. Value $S$ is equal to half of the $200-\mathrm{mm}$ length of the catenometer chain, and $H$ represents the vertical distance from the apical arch curvature to the horizontal line formed by the attachment points of the chain to the caliper arms. This vertical line $H$ divides the chain into halves. The distance between attached ends of the chain was taken as a convenient expression of arch shape; ie, catenary number. (When the apical curvature was great and value $R$ was smaller, the arms of the catenary chain were closer together and the catenary number smaller.)

Data on shape changes were complemented by measurements of arch proportionality whenever enough dental organs were present to provide landmarks for anterior and posterior arch ratios. The anterior arch index was the ratio between the intercanine width and the sagittal distance from that line to the anterior-most top of the dental arch. Arch depth posterior to the intercanine line was proportionately related to the line connecting the right and left distal extremities of the arch and was expressed as a posterior arch ratio. Unlike the catenary analyses, these ratios were based on absolute dimensions at a given magnification. Changes in the area bounded by the dental arch were determined planimetrically.

The sample size of this study did not warrant a more sophisticated mathematical or statistical model. Furthermore, the sample size and sampling methods of this study, like most cross-sectional samples, are generally intended (and restricted) to illustrate trends rather than norms.

\section{Results}

The complex of dental lamina and enamel organs in the human lower jaw showed several changes in shape, proportions, and relative size during the ages $6 \frac{1}{2}$ through 12 weeks in utero. Cross-sectional data analyses suggested that these changes were directly associated with increasing crown-rump length and sequential stages of early tooth formation, and that they were less pronounced once an early morphologic pattern appeared.

Changes in shape of the mandibular dental arch were noted in terms of conformance to a reference geometric catenary curve. These analyses indicated an increasing curvature of the apical arch region that extended from right to left canine dental organs in $81 / 2$-week embryos. This curvature change was shown by generally decreasing values of $R$ (Table 2 ). Concomitantly, the posterior widths of the arch series, as reflected by decreasing catenary number values, decreased with increasing crown-rump length. As a corollary to these changes, the depth (ie, value $H$ ) of the entire arch increased in length. Arrangement of the reconstructed arches on the basis 
TABLE 2

Catenary Analyses of Mandibular Dental ARCH SHAPE*

\begin{tabular}{rcccrr}
\hline No. & $\begin{array}{c}\text { Embryo } \\
\text { No. }\end{array}$ & $\begin{array}{c}\mathrm{H} \\
(\mathrm{cm})\end{array}$ & $\begin{array}{c}\mathrm{R} \\
(\mathrm{cm})\end{array}$ & $\begin{array}{r}\text { Cate- } \\
\text { nary } \\
\text { No. } \\
(\mathrm{cm})\end{array}$ & \multicolumn{1}{c}{$\begin{array}{r}\text { Arch } \\
\text { Area } \\
\left(\mathrm{cm}^{2}\right)\end{array}$} \\
\hline 1 & EH 600 & 8.35 & 1.81 & 9.59 & 32.65 \\
2 & EH 880 & 8.70 & 1.40 & 7.86 & 46.52 \\
3 & EH 231 & 8.60 & 1.51 & 8.17 & 31.80 \\
4 & EH 739 & 8.00 & 2.25 & 10.30 & 29.10 \\
5 & EH 892 & 7.20 & 3.34 & 12.70 & 27.87 \\
6 & EH 785 & 8.70 & 1.40 & 7.95 & 89.30 \\
7 & EH 946 & 8.30 & 1.87 & 9.61 & 56.52 \\
8 & EH 523 & 8.90 & 1.16 & 7.44 & 54.97 \\
9 & EH 479 & 8.90 & 1.16 & 7.44 & 110.00 \\
10 & EH 678 & 8.90 & 1.16 & 7.44 & 80.78 \\
11 & EH 15A & 8.70 & 1.40 & 8.17 & 80.78 \\
12 & EH 882 & 9.10 & 0.94 & 6.36 & 100.65 \\
13 & EH 356 & 9.00 & 1.05 & 6.94 & 144.27 \\
14 & EH 784 & 9.10 & 0.94 & 6.36 & 140.85 \\
15 & EH 628 & 8.10 & 2.12 & 9.93 & 223.23 \\
\hline
\end{tabular}

* Area and catenary values are $\times 50$ actual.

of increasing levels of dental organ development illustrated an early period of catenary nonconformance (Fig 2).
Embryos representing ages $61 / 2$ through early 8 weeks in utero ( 20 to $27 \mathrm{~mm}$, crownrump length) had arches made up of dental lamina and, whenever present, early budstage dental organs for only the incisor and canine teeth (Table 1). Arches in this developmental grouping were generally flattened anteroposteriorly. Composite visual inspection of the remaining arches showed that a general pattern of arch elongation began with the onset of the cap stage of incisor development. This relative conformance to the catenary standard thus occurred in $81 / 2$ through 12-week embryos (29 through 75 mm, crown-rump length).

Changes in arch proportion were measured by using a series of localized depth-width ratios for anterior and posterior arch regions (Tables 3,4). Absolute dimensions of anterior and posterior arches increased with increasing crown-rump length throughout the study. However, more pronounced and consistent increases in intercanine distances, as well as the depth of the arch anterior to this
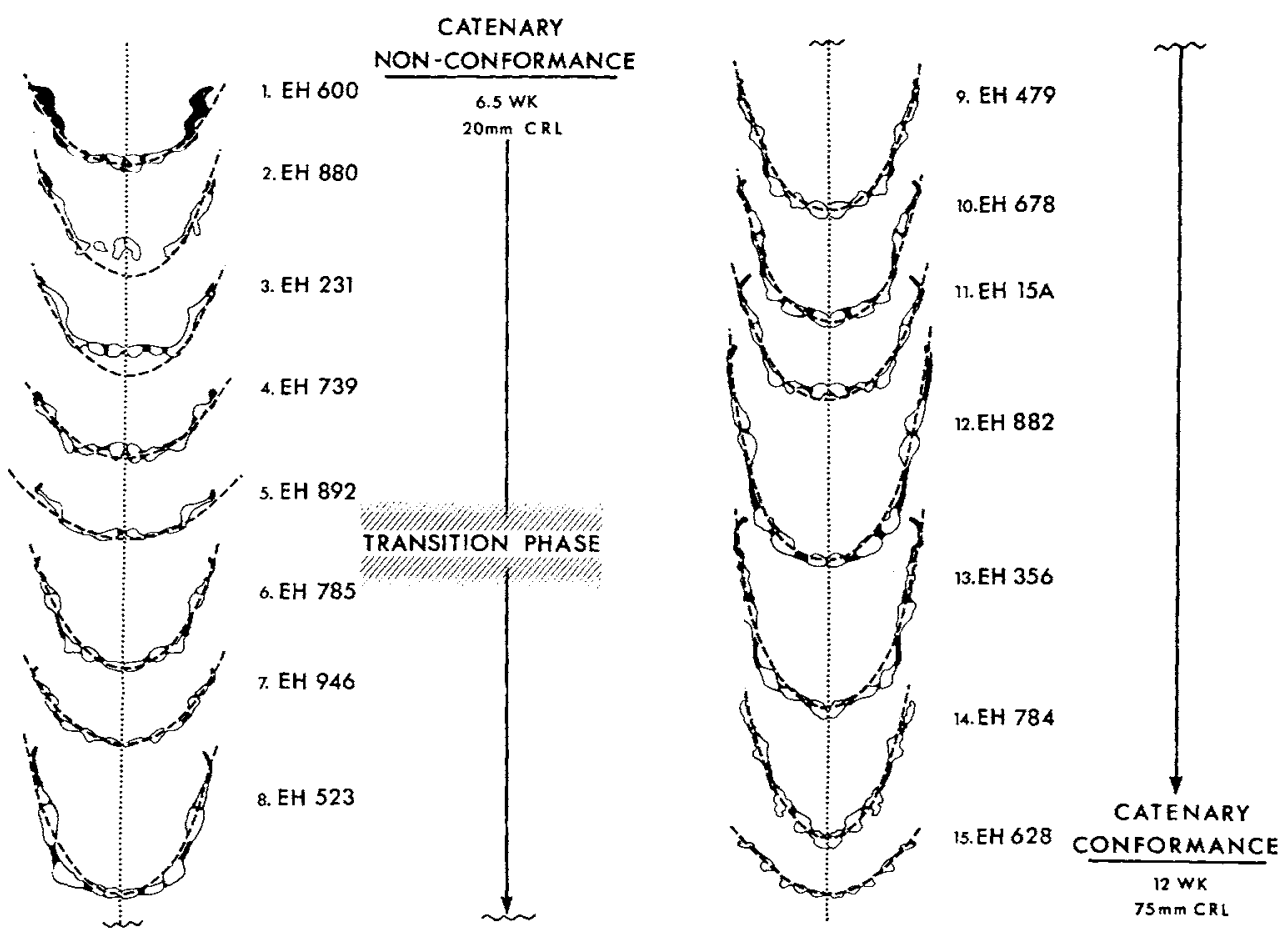

Fis 2.-Summary of observed trends in the elongation of the mandibular dental arch and the morphogenesis of a catenary enamel organ arrangement based on the 15 selected human embryos of this study. The sequence from $6 \frac{1}{2}$ to 12 weeks is arranged according to increasing levels of dental organ maturation. 
intercanine line, appeared at $81 / 2$ weeks. On a relative basis, anterior arch depth-width ratios and the contribution of anterior arch depth to the total arch depth did not change greatly during this period of catenary conformance. Absolute and relative growth patterns for the anterior arch region were similar in the posterior regions. A progressive increase also appeared in the ratios between intercanine arch breadth and posterior arch breadth when related to total arch depth (Table 5), which indicated that the dental arch increased more in width than in length. These general patterns of absolute change and relative stability during the cap stages of tooth development ( $81 / 2$ through 12 weeks of age in utero) were similarly indicated as absolute increases in planimetric determinations of the area bounded by each developing dental arch (Table 2). It should be noted that the arch that had the most development of the series (EH 628; 75-mm crown-rump length) appeared broadly curved and deviated from the patterns observed during the catenary conformance phase of development.

\section{Discussion}

As an integral part of the circumoral functional matrix, the dental arch is influenced by a continuum of genetic and environmental

TABLE 3

ANTERIOR ARCH INDICES*

\begin{tabular}{|c|c|c|c|c|c|c|}
\hline No. & $\begin{array}{c}\text { Embryo } \\
\text { No. }\end{array}$ & $\begin{array}{l}\text { Ant. Arch } \\
\text { Depth } \\
(\mathrm{mm})\end{array}$ & $\begin{array}{c}\text { Intercanine } \\
\text { Breadth } \\
\text { (mm) }\end{array}$ & $\begin{array}{c}\text { Depth/ } \\
\text { Breadth } \\
(\%)\end{array}$ & $\begin{array}{l}\text { Total } \\
\text { Arch }\end{array}$ & $\begin{array}{c}\text { Ant. Arch/ } \\
\text { Total Arch } \\
(\%) \\
\end{array}$ \\
\hline 1 & $\mathrm{EH} 600$ & 14.0 & 64.0 & 21.9 & 54.0 & 26.0 \\
\hline 2 & EH 880 & & & & & \\
\hline 3 & EH 231 & 4.0 & 60.0 & 6.7 & 46.0 & 8.7 \\
\hline 4 & EH 739 & 7.0 & 70.0 & 10.0 & 40.0 & 17.5 \\
\hline 5 & EH 892 & 2.5 & 67.0 & 3.7 & 33.5 & 7.5 \\
\hline 6 & EH 785 & 19.0 & 85.0 & 22.4 & 94.0 & 20.2 \\
\hline 7 & EH 946 & 16.0 & 90.0 & 17.8 & 63.0 & 25.4 \\
\hline 8 & EH 523 & 17.0 & 75.0 & 22.6 & 101.0 & 16.8 \\
\hline 9 & EH 479 & 27.0 & 87.0 & 31.0 & 117.0 & 23.1 \\
\hline 10 & EH 678 & 20.5 & 72.0 & 28.4 & 100.5 & 20.4 \\
\hline 11 & $\mathrm{EH} 15 \mathrm{~A}$ & 18.0 & 83.0 & 21.7 & 93.0 & 19.3 \\
\hline 12 & EH 882 & 27.5 & 72.0 & 38.2 & 136.0 & 20.2 \\
\hline 13 & EH 356 & 27.0 & 90.0 & 30.0 & 150.0 & 18.0 \\
\hline 14 & EH 784 & 50.0 & 92.0 & 54.3 & 153.0 & 32.7 \\
\hline 15 & EH 628 & 28.0 & 164.0 & 17.1 & 116.0 & 24.1 \\
\hline
\end{tabular}

* Absolute values are $X 50$ actual.

+ Measurements and indices for EH 880 were not completed since enamel organs were present but organ centers indeterminable.

TABLE 4

POSTERIOR ARCH INDICES*

\begin{tabular}{|c|c|c|c|c|c|c|}
\hline No. & $\begin{array}{c}\text { Embryo } \\
\text { No. }\end{array}$ & $\begin{array}{l}\text { Post. Arch } \\
\text { Depth }(\mathrm{mm})\end{array}$ & $\begin{array}{c}\text { Post. Arch } \\
\text { Breadth }(\mathrm{mm})\end{array}$ & $\begin{array}{c}\text { Post. Depth/ } \\
\text { Width }(\%)\end{array}$ & $\begin{array}{l}\text { Total Arch } \\
\text { Depth }\end{array}$ & $\begin{array}{l}\text { Post. Depth/ } \\
\text { Total }(\%)\end{array}$ \\
\hline 1 & EH 600 & 40.0 & 112,0 & 35.7 & 54.0 & 74.0 \\
\hline 2 & EH 880 & & & & & \\
\hline 3 & EH 231 & 42.0 & 102.5 & 41.0 & 46.0 & 91.3 \\
\hline 4 & EH 739 & 33.0 & 110.0 & 30.0 & 40.0 & 82.5 \\
\hline 5 & $\mathrm{EH} 892$ & 31.0 & 117.5 & 26.4 & 33.5 & 92.5 \\
\hline 6 & EH 785 & 75.0 & 144.0 & 52.1 & 94.0 & 79.8 \\
\hline 7 & EH 946 & 47.0 & 139.0 & 33.8 & 63.0 & 74.6 \\
\hline 8 & EH 523 & 84.0 & 113.0 & 74.3 & 101.0 & 83.2 \\
\hline 9 & EH 479 & 90.0 & 147.0 & 61.2 & 117.0 & 76.9 \\
\hline 10 & $\mathrm{EH} 678$ & 80.0 & 123.0 & 65.0 & 100.5 & 79.6 \\
\hline 11 & $\mathrm{EH} 15 \mathrm{~A}$ & 75.0 & 111.0 & 67.6 & 93.0 & 80.7 \\
\hline 12 & EH 882 & 108.5 & 102.0 & 106.4 & 136.0 & 79.8 \\
\hline 13 & EH 356 & 123.0 & 123.0 & 100.0 & 150.0 & 82.0 \\
\hline 14 & EH 784 & 103.0 & 168.0 & 61.3 & 153.0 & 67.3 \\
\hline 15 & EH 628 & 88.0 & 335.0 & 26.3 & 116.0 & 75.9 \\
\hline
\end{tabular}

* Absolute values are $\times 50$ actual.

+ Aeasurements and indices for EH 800 were not completed since enamel organs were present but organ centers indeterminable. 
TABLE 5

Regional Dental Arch Brfadth to Total Arch Depth Ratios*

\begin{tabular}{|c|c|c|c|c|c|c|}
\hline No. & $\begin{array}{c}\text { Embryo } \\
\text { No. }\end{array}$ & $\begin{array}{l}\text { Total Arch } \\
\text { Depth }\end{array}$ & $\begin{array}{c}\text { Intercanine } \\
\text { Palatal } \\
\text { Breadth }\end{array}$ & $\begin{array}{c}\text { Anterior } \\
\text { Arch Ratio } \\
(\%)\end{array}$ & $\begin{array}{c}\text { Posterior } \\
\text { Arch } \\
\text { Breadth }\end{array}$ & $\begin{array}{l}\text { Posterior } \\
\text { Arch Ratio } \\
(\%)\end{array}$ \\
\hline 1 & EH 600 & 54.0 & 64.0 & 84.4 & 112.0 & 48.2 \\
\hline 2 & $\mathrm{EH} 880$ & & & & & \\
\hline 3 & EH 231 & 46.0 & 60.0 & 76.7 & 102.5 & 44.9 \\
\hline 4 & EH 739 & 40.0 & 70.0 & 57.1 & 110.0 & 36.4 \\
\hline 5 & EH 892 & 33.5 & 67.0 & 50.0 & 117.5 & 28.5 \\
\hline 6 & EH 785 & 94.0 & 85.0 & 110.6 & 144.0 & 65.3 \\
\hline 7 & EH 946 & 63.0 & 90.0 & 70.0 & 139.0 & 45.3 \\
\hline 8 & EH 523 & 101.0 & 75.0 & 134.7 & 113.0 & 89.4 \\
\hline 9 & EH 479 & 117.0 & 87.0 & 134.5 & 147.0 & 79.6 \\
\hline 10 & EH 678 & 100.5 & 72.0 & 139.6 & 123.0 & 81.7 \\
\hline 11 & $\mathrm{EH} 15 \mathrm{~A}$ & 93.0 & 83.0 & 112.0 & 111.0 & 83.8 \\
\hline 12 & EH 882 & 136.0 & 72.0 & 188.9 & 102.0 & 133.3 \\
\hline $1 \overline{3}$ & EH 356 & 150.0 & 90.0 & 166.7 & 123.0 & 122.0 \\
\hline 14 & EH 784 & 153.0 & 92.0 & 166.3 & 168.0 & 91.1 \\
\hline 15 & EH 628 & 116.0 & 164.0 & 70.7 & 335.0 & 34.6 \\
\hline
\end{tabular}

$*\left[\frac{\text { length }}{\text { breadth }} \times 100\right]$

Measurements and indices for EH 880 were not completed since enamel organs were present but organ centers indeterminable.

processes that span the pre- and postnatal phases of human development. Few will deny the existence or underestimate the importance of this biological concept, but literature on the normal and clinical patterns of postnatal dental arch growth has done little to advance such a concept.

Although the arrangement of embryonic tooth germs in human jaws apparently has not been studied quantitatively until recently, considerable literature is available on the dimensional growth ${ }^{4-8}$ and on changes in shape of the postnatal dental arch as reviewed by Dempster, Adams, and Duddles. ${ }^{9}$ In a descriptive study of a 4-month human embryo, Scott ${ }^{2}$ observed that tooth germs in the upper jaw were arranged in a typical dental arch shape, defined as being best described by a catenary curve, which appeared in dental development with the first appearance of the dental lamina. This work by Scott raised questions about the chronologic development of catenary arch conformance as well as about possible underlying mechanisms. The former question was studied in a series of embryos by Burdi and Lillie, ${ }^{3}$ who supported Scott's suggestion of a catenary arch arrangement of the prenatal maxillary tooth germs. Their quantitative studies also indicated, contrary to Scott's reported qualitative observations, that catenary curvature of human dentition does not appear until approximately $9 \frac{1}{2}$ weeks of age in utero. Before this time, they reported the dental lamina appeared flattened antereposteriorly.

This present study of the lower dental arch arises from Scott's early broad observation on the genesis of catenary arch form for both jaws. It appears that catenary conformance of the lower arch does indeed appear early in prenatal development, but not concomitantly with the initial differentiation of the dental lamina. The arrangement of the dental lamina and 1ooth germs of the lower jaw can be described by a catenary curve first at $8 \frac{1 / 2}{2}$ of embryo age weeks, when the molar enamel organs are in their cap stage of development. Thus, Scott's observation on the prenatal appearance of catenary arch form appears both verified and chronologically refined. The question of possible mechanisms underlying the establishment of this catenary arch arrangement is still unanswered.

At this point, it is important to correlate the few prenatal quantitative studies with similar analyses of dental arch form after birth. Apart from Black's ${ }^{10}$ observations on the variability of the form and placement of teeth in relation to a basic pattern, MacConaill and Scher ${ }^{2}$ were first to do a rigid metric study on the relative variability of tooth cusp positions as a basis for describing an ideal shape of the postnatal human dental arcade. They reported that the geometric catenary, or some regular deviation from a basic catenary, ideally described the curvature of the "common occlusal line." The catenary arrangement of the roots of teeth 
also has been described. ${ }^{9}$ As mentioned earlier, Scott's findings ${ }^{2}$ concurred with the postnatal study in the recognition of a catenary dental arch form before birth.

Much speculation has been directed toward both the phylogenetic significance and ontogenetic mechanisms of dental arch form, whether it be catenary or some other arch occlusion pattern. As a comparative anatomist, Scott ${ }^{2}$ has suggested that the typical arrangement of tooth germs in all toothbearing mammals is in a simple series along a curved arch that conforms to the catenary shape of the ontogenetically older skeletal elements of each jaw, which begins with the cartilaginous nasal capsule and Meckel's cartilage and progresses through the stage of bony mandible and maxillary complex. Deviation from the basic catenary of the arch arrangement, either phylogenetically or ontogenetically, was attributed to differential growth patterns of tooth-bearing alveolar bone. Years before, Cryer ${ }^{11}$ regarded the dentition as being functionally related to the bony framework of occlusion and influenced by such factors as available bone space, anthropologic skeletal differences, and tooth crowding. Similar functional and ontogenetic interrelationships between bones and teeth were recognized by Benninghoff. ${ }^{12}$ The growth of soft body tissues, such as the tongue and circumoral musculature, also has been suggested as a determinant of dental arch shape. ${ }^{13,14}$

Thus, it appears that postnatal normal or clinical changes are growth adjustments of a basic shape esiablished phylogenetically with the appearance of tooth-bearing mammals and, in man, ontogenetically with the embryonic appearance of deciduous dental organs. Such a summary statement has several developmental implications. First, the suggestion that the shape of the postnatal dental arch may be identified in utero emphasizes the initial thesis of the present study that body growth, in general, reflects a continuum of developmental processes. Second, and specific to this study, is the restatement of the earlier posed question on how the morphologic or functional maturation, or both, of various components of the circumoral matrix might influence the transition of the lower dental arch from an anteroposteriorly flattened one at approximately 8 weeks in utero to an arch with a shape that can be described by a catenary curve.
Ontogenetically, such a discussion must be focused on the morphologic and functional maturation of key tissues surrounding the developing dental arch, until the onset of catenary conformance at the end of the second month. During this time, undifferentiated mesenchymal tissue and such mesenchymal derivatives as the skeleton and muscle may influence the dental arch by acting as morphologic templates and growth vectors. It is during this critical time, between the sixth and eighth weeks, that the most dynamic events occur in the embryogenesis of the face. Classically described, major facial primordia appear as epithelium-covered surface elevations that overlie deeper centers of mesenchymal proliferation. At this time, mesenchymal proliferation and migration underlie the topology, differential growth, migration, and consolidation mechanisms of fusion and merging that yield an embryonic face that is recognizably human. ${ }^{15,16}$ If a vector role were to be assigned to any one tissue at this stage, it would be to the volumetrically dominant mesenchymal growth centers. The migration of early facial primordia until the seventh week, leading to proportional changes, has been described by Avery. ${ }^{17}$

Skeletal development also coincides with the early appearance of the mandibular dental lamina. After the period of mesenchymal dominance, mesenchymal cells begin to condense and, at 7 weeks, provide an early indication of the chondrocranium from which cartilage elements project into the upper and lower facial mesenchymal primordia as the nasal capsule and Meckel's cartilage, respectively. ${ }^{18.19}$ At approximately the early eighth week, membranous bone centers can be seen lateral to both the nasal capsule and Meckel's cartilage. These centers give rise to the osseous maxillary complex and mandible that will progressively replace the medially located visceral chondrocranium. ${ }^{20}$ Thus, when the mandibular dental arch is composed of dental lamina and dental organs, and when significant changes in arch shape occur, cartilage, not bone, provides the supportive facial skeleton for the overlying soft tissues. In addition to this supportive role, the visceral chondrocranium may be a morphologic template around which facial bones differentiate, and could well be the dominant growth vector of the face. This suggestion of chondrocranial supportive, template, and vector 
roles may provide additional emphasis to Scott's ${ }^{2}$ argument, which attributes the embryonic appearance of a catenary dental arch to the catenary shape of the nasal capsule and Meckel's cartilage. The importance of chondrocranial growth as a vector has been related to the abnormal development of the face and to cleft palate. ${ }^{21}$

Since catenary arch arrangement appears to be related to a similarly shaped cartilaginous facial skeleton, and both are recognizable prior to observed neuromuscular activity in the orofacial region, ${ }^{22,23}$ the influence, if any, of circumoral musculature on shaping the catenary arch at the eighth week is uncertain. ${ }^{24}$ Certainly the tongue should also be considered as a possible influence in shaping the dental lamina. Beginning with the fifth week, the body of the tongue is indicated by primordia that progressively coalesce. By the seventh week, the tongue increases in volume, length, and width. Although muscle begins to differentiate in the body of the tongue at 6 to 7 weeks, ${ }^{25}$ the time that functional tongue activity begins is not known. Hewer ${ }^{26}$ described a rich nerve supply to the tongue and many terminal endings on muscle fibers at 7 weeks, but he also found that differentiation of adult motor end plates starts at about 20 weeks. Neuromuscular maturation of the tongue as a basis for either reflex or voluntary functional activity needs further study. It now appears that tongue development in general occurs concomitantly with dental arch morphogenesis and may, by its volume or activity, exert a shaping influence on the elongation of the dental arch. ${ }^{27}$

As with most developmental phenomena, time is a critical factor in attributing the establishment and maintenance of dental arch shape to any one tissue or combination of tissues of the circumoral matrix. Moreover, to get beyond the relationships of association that are inherent in descriptive studies, further efforts must take an experimental course if causal relationships are to be provided as an explanation of normal and clinical growth patterns of the perinatal and juvenile human dental arch. Correlation of these descriptive and experimental observations should then provide some needed insight concerning the regulation of interarch developmental synchrony as a basis for occlusion, the functional activity of both the tongue and circumoral musculature in de- termining dental arch form, the inductive or mechanical interrelations (or both) of contiguous cartilaginous, bony, and dental tissues of the prenatal circumoral complex, and the genetic patterns underlying the phylogenetic and ontogenetic patterns of dental arch development.

\section{Conclusions}

Changes in dental arch shape and size for serially sectioned embryos, $6 \frac{1}{2}$ through 12 weeks in utero, were measured through graphic reconstructions and expressed in terms of conformity to the arbitrarily chosen catenary curve. Additional data were derived from planimetric and regional arch proportionality ratios.

The cross-sectional data demonstrated that the mandibular arch first appears as an anteroposteriorly flattened arch made up of dental lamina and progressively elongates, with the sequential appearance of the enamel organs, so that it conforms to a catenary curve at approximately $81 / 2$ weeks. A comparison of maxillary and mandibular embryonic arch development indicated a general synchrony in morphogenesis.

In addition, the developmental basis for postnatal dental arch shapes, indicated as catenary by prosthodontists, was discussed. This study has put into quantitative terms certain specific growth patterns that have been described previously only in subjective terms.

\section{References}

1. MacConaill, M.A., and Scher, E.A.: Ideal Form of the Human Dental Arcade with Some Prosthetic Application, Dent Rec 69: 285-302, 1949.

2. ScotT, J.H.: The Shape of the Dental Arches, J Dent Res 36:996-1003, 1957.

3. Burdi, A.R., and Lillie, J.H.: A Catenary Analysis of the Maxillary Dental Arch during Human Embryogenesis, Anat Rec 154: 13-20, 1966.

4. Shapiro, H.H.: Growth in the Mandibular Dental Arch, J Dent Res 20:335-340, 1941.

5. Pettenella, L., and Menini, G.: The Relationship between the Transverse Diameters of Face, Upper Arch and Teeth, Europ Orthodont Soc Trans 39:281-284, 1963.

6. Bernstein, K.: Dynamic Somatologic Characteristic of the Dental Arch in Correlation with Skull and Physiognomic Signs, Europ Orthodont Soc Trans 40:447-461, 1964.

7. Sillman, J.H.: Dimensional Changes of the Dental Arches: Longitudinal Study from 
Birth to 25 Years, Amer J Orthodont 50: 824-842, 1964.

8. Van Reenan, J.F.: The Dental Arch, $J$ Dent Assoc, South Africa 19:198-211, 1964.

9. Dempster, W.T.; Adams, W.J.; and DudDLES, R.A.: Arrangement in the Jaws of the Roots of the Teeth, JADA 67:779-797, 1963.

10. BlaCK, G.V.: Descriptive Anatomy of the Human Teeth, Philadelphia: Wilmington Dental Mfg. Co., 1894, pp 135-148.

11. Cryer, M.H.: Typical and Atypical Occlusion of the Teeth in Relation to the Correction of Irregularities, Dent Cosmos 46: 713-733, 1904.

12. BENNINGHOFF, A.: Spaltlinien am Knochen, eine Methode zur Ermittlung der Architektur platter Knochen, Verhandl d Anat Gesellch 34:189-206, 1925.

13. HovelL, J.: The Genetically Imposed Limitations of Orthodontic Treatment, European Orthodont Soc Trans 32:68-75, 1956.

14. Graber, T.M.: Orthodontics: Principles and Practice, Philadelphia: W. B. Saunders Co., 1966, chapt 6, pp 249-325.

15. Streeter, G.L.: Developmental Horizons in Human Embryos: Age Groups XI to XXIII, Carnegie Contrib Embryol Reprint Vol. 2, 1951.

16. Patten, B.M.: "The Normal Development of the Facial Region," in S. PruZansky, ed.: Congenital Anomalies of the Face and Associated Structures, Springfield: Charles C Thomas Co., 1961, chapt 1, pp 11-45.

17. Avery, J.K.: Children with Cleft Lip and Cleft Palate: Embryological Basis for De- fects of the Face and Palate, Univ. Michigan Cont Educ Series No. 93, 1961, pp 19-36.

18. KERNAN, J.D.: The Chondrocranium of a $20 \mathrm{~mm}$. Human Embryo, J Morphol 27:605$645,1920$.

19. LEWIS, W.H.: The Cartilaginous Skull of a Human Embryo Twenty-one Millimeters in Length, Carnegie Contrib Embryol 9:299$324,1920$.

20. Macklin, C.C.: The Skull of a Human Fetus of $40 \mathrm{~mm}$, Amer J Anat 16:317-426, 1914.

21. Avery, J.K.: The Nasal Capsule in Cleft Palate, Anat Anz 109:722-726, 1961.

22. Hooker, D.: The Prenatal Origin of $B e-$ havior, Lawrence, Kan., University of Kansas Press, 1952, pp 54-86.

23. Windle, W., and Fitzgerald, J.: Development of the Human Mesencephalic Trigeminal Root and Related Neurons, I Comp Neurol 77:597-608, 1942.

24. ScotT, J.H.: What Determines the Form of the Dental Arches? Orthodont Rec 1:15-16, 1958.

25. KeITH, A.: Human Embryology and Morphology, Baltimore: Wm. Wood Co., 1933, chapt 19, pp 288-300.

26. HEwer, E.E.: The Development of Nerve Endings in the Human Fetus, $J$ Anat 69: 369-379, 1935.

27. BRASH, J.C.; MCKEAG, H.T.A.; and SCOTT, J.H.: The Aetiology of Irregularity and Malocclusion of the Teeth, London: Dent. Bd. United Kingdom, 1956, chapt 6, pp 200-202. 